\title{
Rectal Prolapse: Review According to the Personal Experience
}

\author{
Seo-Gue Yoon \\ Department of Surgery, Seoul Song Do Hospital, Seoul, Korea
}

The aim of treatment of rectal prolapse is to control the prolapse, restore continence, and prevent constipation or impaired evacuation. Faced with a multitude of options, the choice of an optimal treatment is difficult. It is best tailored to patient and surgeon. Numerous procedures have been described and are generally categorized into perineal or abdominal approaches. In general, an abdominal procedure has associated with lower recurrence and better functional outcome than perineal procedures. The widespread success of laparoscopic surgery has led to the development of laparoscopic procedures in the treatment of complete rectal prolapse. In Korea, there has been a trend toward offering perineal procedures because of the high incidence of rectal prolapse in young males and its being a lesser procedure. Delorme-Thiersch procedure has appeal as a lesser procedure for patients of any age or risk category, especially for elderly low-risk patients, patients with constipation or evacuation difficulties, young males, and patients with symptomatic hemorrhoids or mucosal prolapse. Laparoscopic suture rectopexy is recommended for either low-risk female patients or patients who are concerned with postoperative aggravation of their incontinence.

Keywords: Rectal prolapse; Delorme procedure; Delorme-Thiersch procedure

\section{INTRODUCTION}

Rectal prolapse is a disease in which the rectum is prolapsed to the anal canal, and the prolapse is classified according to degree as a complete full thickness rectal prolapse, a mucosal prolapse, or an internal or occult rectal prolapse. The following anatomical defects are frequently associated with rectal prolapse patients: diastasis of the levator ani muscle, a deep pouch of Douglas, a redundant sigmoid colon, a lack of normal fixation of the rectum with a mobile mesorectum, and the patulous anus. Together with such anatomical defects, the small intestine is located in front of the rectum; thus, during defecation, the force pushing the rectum to the anal direction is augmented, so rectal prolapse occurs more readily.

Received: January 19, 2010 Accepted: July 26, 2010

Correspondence to: Seo-Gue Yoon, M.D.

Department of Surgery, Seoul Song Do Hospital, 366-144 Sindang 3-dong,

Jung-gu, Seoul 100-453, Korea

Tel: +82-2-2250-7368, Fax: +82-2-2233-8528

E-mail: seogue@naver.com

(c) 2011 The Korean Society of Coloproctology

This is an open-access article distributed under the terms of the Creative Commons Attribution NonCommercial License (http://creativecommons.org/licenses/by-nc/3.0) which permits unrestricted noncommercial use, distribution, and reproduction in any medium, provided the original work is properly cited.
The incidence of rectal prolapse reported in Western and Korean statistics differ greatly. Even though both Western and Korean statistics report that in females, the incidence is increased after 50 years of age and the maximal incidence is reached in the 70 s and that in males, the incidence is distributed evenly over all age groups, the incidence according to gender is greatly different. According to the Western statistics, rectal prolapse is more apt to occur in females, with more than $80 \%$ of the patients being female. In Korea, however, the incidences in males and females are comparable; thus, the incidence in young males is relatively high [1].

The patients with rectal prolapse suffer from not only a prolapsed rectum but also associated dysfunction. More than $50 \%$ of the patients suffer from fecal incontinence. Fifteen to sixty-five of the patients have constipation, and excessive pushing during defecation induces injury of the mucosa of the rectal anterior wall, so the patient may also present with a solitary rectal ulcer.

The purpose of treatment for rectal prolapse is correction of the prolapsed rectum as well as recovery and prevention from defecation dysfunction postoperatively. Therefore, when selecting surgical methods, operator should understand exact causative factors and anatomical variation. The health condition of the patient, the mortality rate, the recurrence rate, and the possibility of maintaining and recovering defecation function should 
be considered. Nevertheless, until now, ideal surgical methods have not been available; moreover, numerous types of surgeries have still been introduced and attempted. Most surgical techniques developed until now have both advantages and shortcomings, however, a substantial number of them are used only by the investigator. Hence, this paper briefly summarizes various surgical methods and introduces the surgical techniques considering characteristics of Korean patients at our institution.

\section{SURGICAL METHODS FOR RECTAL PROLAPSE}

Surgical methods can be broadly classified as abdominal procedures and perineal procedures. Abdominal procedures are techniques for fixating of the rectum to the sacral bone by using diverse methods, and the excessive sigmoid colon or rectum may be resected in combination. Perineal procedures are techniques for shortening of the prolapsed rectum by cutting or plicating the prolapsed rectum. In addition, techniques for strengthening of weakened pelvic floor muscles may be used.

\section{Abdominal approaches}

Numerous abdominal approaches have been introduced, and the difference among the techniques is merely the level of rectal mobilization, the method fixating the rectum, inclusion or exclusion of bowel resection, and the use of laparoscopy.

\section{Suture rectopexy}

Surgical methods are to mobilize the rectum from adjacent tissues completely and to suture and anchor the rectum to the sacrum. In this technique, adhesion progresses due to fibrosis, keeping the rectum anchored to the sacrum. Mortality is very low, and the recurrence rate is $0-3 \%$. After surgery, associated fecal incontinence is improved, but the relief from constipation varies with the investigators [2-5].

\section{Prosthetic/mesh rectopexy}

Based on the assumption that when foreign materials are used, stronger fibrosis and adhesion than simple suture could be induced, the rectopexy method uses the fascia lata, non-absorbable mesh (nylon, prolene, marlex, ivalon, teflon), or absorbable mesh (dexon, vicryl). Depending on the fixation site, the method is classified as posterior mesh rectopexy or anterior sling rectopexy.

\section{Posterior mesh rectopexy}

The surgical method mobilizes the rectum completely, inserts synthetic materials or a mesh between the sacrum and the rectum, and performs suturing and fixation to the sacral fascia. In cases in which an ivalon sponge is used, mortality is $0-3 \%$, and the recurrence rate is approximately $3 \%[6,7]$. The improvement in fecal incontinence is $3-40 \%$, and the relief from constipation varies with investigators.

The most serious complication of rectopexy using the ivalon sponge is the development of pelvic sepsis, which occurs in 2$16 \%$ of the cases and is a major cause of death. In the 1980s, the ivalon sponge was widely used, but after 1994, its use has not been reported. Instead of the ivalon sponge, other non-absorbable materials have been used. Recently, absorbable meshes have been used, but regardless of the materials used, the outcomes have been comparable; mortality is $0-1 \%$, and the recurrence rate is $0-6 \%$ [8-13]. Associated fecal incontinence shows improvement in most cases; nonetheless, the level of relief from constipation shows differs [8-13]. Particularly, it has been reported that in the cases using the ivalon sponge, the incidence of pelvic abscess is high, and the incidence is increased in cases in which a bowel resection was performed. It has also been reported that by performing posterior mesh rectopexy using other materials and without bowel resection, low complications are shown; thus, it is a good surgical method $[11,14,15]$.

\section{Ripstein procedure (anterior sling rectopexy)}

The Ripstein procedure was introduced by Ripstein [16] in 1952. The procedure includes a complete mobilization of the rectum and a subsequent fixation of it to the facia lata or with synthetic materials to the anterior wall of the rectum and fixates the sling to the sacrum by sutures. Mortality is $0-2.8 \%$, the recurrence rate is $0-13 \%$, and most associated fecal incontinence is improved. If the sling is squeezed excessively between the intestine and the sacrum, constipation or fecal impaction may develop, and the incidence of constipation varies depending on investigators [8, 11, 17-21]. Complications directly associated with the sling are high (16.5\%), but the incidence of reoperation is low (4.1\%). Indications of reoperation are fecal impaction, small bowel obstruction, rectal stricture, pelvic sepsis, rectal erosion, and hemorrhage [22].

\section{Resection}

After a rectal resection, it has been commonly observed that a strong adhesion between rectal anastomosis and sacrum enables to fix rectum to sacrum. For that reason, bowel resection has been applied to the treatment of rectal prolapse. Additional theoretical advantages of bowel resection are as follows: by resection of the excessive rectum, torsion or volvulus of the sigmoid colon can be prevented. Also, by shortening the left colon, the mobility of the left colon supported by the diaphragm ligaments almost disappears, which helps prevent recurrence. In addition, relief from constipation can be anticipated in some patients [23,24].

The combined procedure of resection of the sigmoid colon and abdominal rectopexy (resection rectopexy, Frykman-Goldberg procedure) is a procedure that combines the advantages of a sigmoid colectomy and rectopexy. Mortality is $0-6.7 \%$, and the recurrence rate is $0-5 \%$. In most cases, both fecal incontinence and constipation are improved [10, 12, 25-28]. The relief from 
constipation is due to reduced outlet obstruction [10] or the prevention of twisting of the excessively long large intestine [29]. In male patients, wide pelvic dissection may induce serious sexual dysfunction [25].

Moreover, it had been performed at some institutions in the past due to its simple technique. However, presently, it is not widely performed.

\section{Laparoscopic rectopexy}

In comparison with open surgery, laparoscopic surgery has the advantages of less pain, shortened hospital stay, early recovery, and early return for work [30,31]. All procedures applied to open abdominal surgery have been attempted by laparoscopy; nonetheless, among them, laparoscopic rectopexy is favored because the procedure is simple, and the bowel anastomosis area can be avoided. The rate of surgical complications is $0-3 \%$, and recurrence is $0-10 \%$. Regarding surgical complications, recurrence rate, and the correction of associated dysfunction, its effectiveness is comparable to that of a laparotomy [26, 30-40].

\section{Role of mesh in rectopexy}

Recently, the use of mesh in rectopexy has been increasingly opposed. In the Ripstein procedure, fatal complications, such as rectal erosion, fistula, and rectal stricture, may be caused by mesh slings, and it has been proven that the adhesion anticipated by using mesh is not effective [23] and that the ivalon sponge is destroyed after a long time and remains in the body for 5 years [6]. Presently, numerous investigators believe that sufficient rectopexy can be achieved using only simple sutures without the use of foreign materials [3, 19, 23, 41, 42].

\section{Preservation of lateral ligaments}

The left colon and the rectum are controlled by the autonomic nerve system through the lateral ligaments. Therefore, in rectopexy, the resection of the lateral ligaments may induce the denervation of the rectum and, consequently, constipation $[13,15]$. The preservation of the lateral ligaments may prevent the worsening of constipation after surgery, but due to insufficient dissection of the rectum, it increases the possibility of recurrence [43].

\section{Perineal approaches}

The perineal approach could avoid a laparotomy; thus, it has advantages even when applied to high-risk patients. The most frequently applied procedures are the Delorme procedure and the Altemeier procedure (perineal rectosigmoidectomy). The Thiersch procedure has been applied; however because it prevents the prolapse of the rectum mechanically, it cannot be used as radical surgery for rectal prolapse, and due to its high rates of recurrence and complications, presently, it is not recommended.

Delorme procedure

The Delorme procedure was developed by Delorme in 1990. It peels the mucosa of the prolapsed bowel, plicates the remaining muscle layer and performs mucosal anastomosis. The rate of complications is $0-4 \%$, and the recurrence rate is $4-38 \%$. Most patients show the improvement of fecal incontinence after surgery [20, 21, 44-47].

\section{Altemeier procedure}

The Altemeier procedure reinforces the pelvic floor muscle after resecting the prolaped bowel, closing the pouch of Douglas, and performing a lavatoplasty in combination and should remove the prolapse and improve incontinence. The rate of surgical complications is $0-5 \%$, and the recurrence rate is $0-16 \%$ [48-53]. The incidence of anastomotic leakage is very rare. If lavatoplasty is performed in combination, the improvement of fecal incontinence has been reported to be superior to the Delorme procedure [50]. For cases with small rectal prolapsed, the length of prolapse is less than $3 \mathrm{~cm}$, or with incomplete rectal prolapse, the Altemeier procedure is difficult technically [54].

\section{Delorme-Thiersch procedure}

If the prolapsed rectum is shortened by using the Delorme procedure and subsequently the relaxed anal sphincter is supported by using the Thiersch procedure, the shortcomings of both procedures have been reported to be reduced. Thus, recurrence is lowered, and good postsurgical results are obtained [55].

\section{COMPARISON OF THE PROCEDURES}

Scaglia et al. [8] compared 16 cases in which a post posterior mesh rectopexy had been performed with 12 cases in which the Ripstein procedure had been performed. In both groups, none of cases showed relief from constipation or defecation disorders. However, in this study, the subject patient group was too small. Novell et al. [4] compared 31 cases in which a polyvinyl alcohol sponge procedure had been performed with 32 cases in which a suture rectopexy had been performed. In the suture rectopexy group, relief from fecal incontinence and constipation was small. Also, because of the concern of infection caused by the use of alcohol sponges, their use should be avoided.

In a prospective study in 1992, Luukkonen et al. [10] compared 15 cases in which only rectopexy had been performed with 15 cases in which a sigmoid resection in conjunction with rectoplexy had been performed. In cases in which a colectomy had also been performed, surgical complications were not increased, and after surgery, the effect of constipation was reduced.

In 2001, Benoist et al. [35] analyzed 48 cases in which rectopexy had been performed and compared rectopexy using simple sutures, rectopexy using mesh, and rectopexy in combination with resection. The results showed that laparoscopic suture rectopexy was safe and effective, that the improvement of fecal incontinence among the groups was not different, and that rectopexy using simple sutures was comparable to rectopexy using mesh. 
Kim et al. [48] reported in 1999 the results of analyzing 372 complete rectal prolapse cases treated during 19 years. The results showed that after performing the combination procedure of sigmoid colectomy and abdominal rectopexy, recurrence was lower. After the Altemeier procedure, surgical complications were fewer and the hospital stay was shorter. Thus, it was a surgical procedure that could be recommended for the elderly highrisk group.

Yakut et al. [25] compared 94 cases in which the Delorme procedure and rectopexy had been performed and reported that in males undergoing rectopexy, the most serious complication was sexual dysfunction after surgery and that both the Delorme procedure and rectopexy were effective in treating rectal prolapsed. They also reported that a wide pelvic dissection performed during rectopexy might induce severe sexual dysfunction after surgery.

Deen et al. [27] compared rectopexy and the Altemeier procedure and reported that after rectopexy, the function of the anal sphincter and the rectal storage ability were preserved. Thus, the improvement of dysfunction was excellent.

Agachan et al. [50] compared and analyzed the Delorme procedure, the Altemeier procedure, and a combination of the Altemeier procedure with lavatoplasty. Recurrence was the highest in the Delorme group and the lowest in the combination group with lavatoplasty group. Fecal incontinence was improved by all procedures, but lavatoplasty showed the best results. Thus, the combination with lavatoplasty showed the best short-term outcomes. Yoon et al. [56] compared 38 cases in which the Altemeier procedure had been performed with 44 cases in which the Delorme procedure had been performed in complete rectal prolapse patients. Except for the operation time being noticeably longer in patients who underwent the Altemeier procedure, postsurgical bowel function, anorectal test findings, the complication rate, the recurrence rate and the surgery satisfaction level were comparable (Table 1). Therefore, regardless of the selection of surgery, which is usually according to the preference of the surgeon, identical short-term outcomes are obtained.

Yoon et al. [56] compared and analyzed 50 cases in which the Delorme procedure alone had been performed with 50 cases in which the Delorme-Thiersch procedure had been performed. After surgery, the improvement of the anal sphincter function and the indices of the improvement of fecal incontinence and constipation of the two groups were not significantly different. Recurrence was reported in 6 cases in which the Delorme pro-

Table 1. Comparison between the Altemeier and the Delorme procedures

\begin{tabular}{lccc}
\hline Parameters & Altemeier & Delorme & P-value \\
\hline Length of resection (cm) & 11.7 & 12.0 & NS \\
Operative time (min) & 80.3 & 53.1 & $<0.0001$ \\
Morbidity & $2 / 38$ & $2 / 44$ & NS \\
Mortality & 0 & 0 & NS \\
Length of hospital stay (day) & 6 & 6 & NS \\
Recurrence (mucosal/complete) & $1 / 2$ & $2 / 2$ & NS \\
Maximum resting pressure (mm Hg) & 24.1 & 25.7 & NS \\
$\begin{array}{l}\text { Maximum squeezing pressure (mm Hg) } \\
\text { Incontinence score }\end{array} \quad 84.2$ & 92.3 & NS \\
$\quad$ preoperative/postoperative) & $11.9 / 6.7$ & $6.4 / 2.5$ & NS \\
Constipation score & & & \\
$\quad$ preoperative/postoperative) & $9.6 / 4.3$ & $8.0 / 3.4$ & NS \\
Subjective satisfaction score & 79 & 85.0 & NS \\
\hline
\end{tabular}

NS, not significant.

Table 2. Comparison between the Delorme and the Delorme-Thiersch procedures

\begin{tabular}{|c|c|c|c|}
\hline & Delorme & Delorme-Thiersch & P-value \\
\hline Operative time (min) & 50.7 & 62.4 & $<0.01$ \\
\hline Follow-up (mo) & 25.1 & 22.3 & \\
\hline Early complication & 0 & 0 & \\
\hline $\begin{array}{l}\text { Late complication } \\
\text { Infection }\end{array}$ & $\begin{array}{l}0 \\
0\end{array}$ & $\begin{array}{l}1 \\
1\end{array}$ & \\
\hline Recurrence & 6 & 0 & 0.013 \\
\hline Mucosal & 3 & 0 & \\
\hline Complete & 3 & 0 & \\
\hline MRP (mm Hg, preoperative/postoperative) & $37.7 / 36.3$ & $38.9 / 44.5$ & NS \\
\hline MSP (mm Hg, preoperative/postoperative) & 100.9/100.6 & $111.9 / 132.4$ & NS \\
\hline Incontinence score (preoperative/postoperative) & $8.2 / 4.6$ & $8.4 / 6.8$ & NS \\
\hline Constipation score (preoperative/postoperative) & $9.2 / 4.1$ & $9.4 / 4.6$ & NS \\
\hline Satisfaction (0-100) & 85.3 & 90.5 & NS \\
\hline
\end{tabular}

MRP, maximum resting pressure; MSP, maximum squeezing pressure, NS, not significant. 
cedure alone had been performed. On the other hand, after the Delorme-Thiersch procedure, recurrence was not detected; thus, recurrence had been noticeably prevented. Early surgical complications were not detected in the two groups. One year after surgery, infection caused by the insertion of the Thiersch ring was detected, and even after the removal of the ring, recurrence was not detected (Table 2). The authors stated that the DelormeThiersch procedure could prevent the shortcomings of recurrence associated with the Delorme procedure, that it does not have adverse effects on the anus and defecation function, that it is an effective procedure without the diverse complications caused by Thiersch procedure, and that it could be applied as a standard perineal procedure.

In addition, Yoon et al. [57] compared 174 cases in which the Delorme-Thiersch procedure had been performed with 109 cases in which laparoscopic rectopexy had been performed. In the comparison with laparoscopic rectopexy, the operation time of the Delorme-Thiersch procedure was noticeably shorter, the risk for male sexual function was absent, recurrence was infrequent, and comparable improved anal function was shown. Nonetheless, due to the decreased volume of the rectum after surgery, the improvement of fecal incontinence was inferior; on the other hand, the relief from constipation was superior. Both procedures showed a high index of quality of life and a high level of satisfaction with the surgery (Table 3 ). Hence, laparoscopic rectopexy may be recommended for females without risk of sexual dysfunction in the low risk group for surgery or in patients for whom deterioration of fecal incontinence after surgery is a concern, and the Delorme-Thiersch surgery may be recommended for all rectal prolapse patients except for patients for whom the risk of the deterioration of fecal incontinence after surgery is a concern.

\section{THE STANDARD FOR THE SELECTION OF SURGERY}

Summarizing studies reported until now, in comparison with the perineal approach, the recurrence associated with the ab- dominal approach is low, and the improvement of fecal incontinence is superior. Thus, except for elderly patients of the high risk group, the abdominal approach has been recommended. Simple rectopexy is sufficient, and the use of meshes and other foreign materials should be restricted. For patients with constipation or patients with a long excess bowel, resection may be performed in combination. Focusing on the prevention of recurrence, lateral ligaments should be resected, and for the prevention of the deterioration of constipation, lateral ligaments should be preserved. If laparoscopic surgery is familiar to the surgeon, laparoscopic procedures should be performed.

For high risk patients, the perineal approach should be selected. Since its recurrence rate is higher than that of the abdominal approach, the possibility of a reoperation should be discussed sufficiently. The Delorme procedure or the Altemeier procedure is selected depending on the length of prolapse and on the experience and familiarity levels of the surgeon. Recently, the perineal approach is favored in Korea due to shortening of hospital stay, early return to normal life, low surgical stress, and good cosmetic effect, even if the possibility of recurrence is somewhat high.

I prefer the Delorme-Thiersch procedure because the operation time is short and general anesthesia is not required, so it can be applied to the high risk group. In addition, recurrence and recovery bowel function after surgery are not inferior to those of the abdominal approach, it does not cause male sexual dysfunction, and hemorrhoid or the mucosal prolapse associated with a complete rectal prolapse can be treated simultaneously; thus, it can be applied to all rectal prolapse patients except for those in whom deterioration of fecal incontinence after surgery is a concern. For low risk female patients who concerns for postoperative fecal incontinence, abdominal rectopexy should be selected.

\section{CONCLUSION}

Although many kinds of surgical methods for rectal prolapse have been introduced, there is no surgical procedure that satis-

Table 3. Comparison between the Delorme-Thiersch procedure and laparoscopic structure rectopexy

\begin{tabular}{lccc}
\hline Parameters & Delorme-Thiersch & Laparoscopic rectopexy & P-value \\
\hline Operative time (min) & 48.4 & 90.9 & $3 / 109$ \\
Morbidity & $5 / 174$ & Hemorrhage (1) & NS \\
& Infection (1) & Retrograde ejaculation (2) \\
& Rectovaginal fistula (1) & 0 & NS \\
Mortality & Anastomosis stricture (3) & 6 & NS \\
Length of hospital stay (day) & 0 & $4 / 3$ & NS \\
Recurrence (mucosal/complete) & 6 & 42.3 & NS \\
Maximum resting pressure (mm $(\mathrm{Hg})$ & $0 / 1$ & &
\end{tabular}

NS, not significant. 
fies all kinds of postoperative complication. Similar to other diseases, when individualized treatments are applied to the treatment of rectal prolapse, treatment outcomes are unavoidably good; nonetheless, a standard surgery based on comparative studies considering gender, associated diseases, associated defecation disorders, age, and the risk for surgery has not been suggested. The incidence of rectal prolapse is low and many diverse surgical methods have been introduced; thus, it is difficult to compare diverse surgical methods on a sufficient number of patients.

I recommends the Delorme-Thiersch procedure because the development pattern of rectal prolapse in Korean patients is different from that in Western patients; thus, a perineal approach must be selected in many cases. The Delorme-Thiersch procedure can be performed effectively in all rectal prolapse patients, and treatment outcomes comparable to the abdominal approach can be anticipated. Finally, the development of improved ideal surgical methods considering Korea's current situation is expected.

\section{CONFLICT OF INTEREST}

No potential conflict of interest relevant to this article was reported.

\section{REFERENCES}

1. Yoon SG, Lee KR, Cho KA, Hwang DY, Kim KU, Kang YW, et al. Clinical and physiologic characteristics of rectal prolapse in males. J Korean Soc Coloproctol 2000;16:223-30.

2. Briel JW, Schouten WR, Boerma MO. Long-term results of suture rectopexy in patients with fecal incontinence associated with incomplete rectal prolapse. Dis Colon Rectum 1997;40:1228-32.

3. Carter AE. Rectosacral suture fixation for complete rectal prolapse in the elderly, the frail and the demented. Br J Surg 1983;70: 522-3.

4. Novell JR, Osborne MJ, Winslet MC, Lewis AA. Prospective randomized trial of Ivalon sponge versus sutured rectopexy for fullthickness rectal prolapse. Br J Surg 1994;81:904-6.

5. Khanna AK, Misra MK, Kumar K. Simplified sutured sacral rectopexy for complete rectal prolapse in adults. Eur J Surg 1996;162: 143-6.

6. Penfold JC, Hawley PR. Experiences of Ivalon-sponge implant for complete rectal prolapse at St. Mark's Hospital, 1960-70. Br J Surg 1972;59:846-8.

7. Morgan CN, Porter NH, Klugman DJ. Ivalon (polyvinyl alcohol) sponge in the repair of complete rectal prolapse. Br J Surg 1972; 59:841-6.

8. Scaglia M, Fasth S, Hallgren T, Nordgren S, Oresland T, Hulten L. Abdominal rectopexy for rectal prolapse. Influence of surgical technique on functional outcome. Dis Colon Rectum 1994;37:805-13.

9. Sayfan J, Pinho M, Alexander-Williams J, Keighley MR. Sutured posterior abdominal rectopexy with sigmoidectomy compared with
Marlex rectopexy for rectal prolapse. Br J Surg 1990;77:143-5.

10. Luukkonen P, Mikkonen U, Jarvinen H. Abdominal rectopexy with sigmoidectomy vs. rectopexy alone for rectal prolapse: a prospective, randomized study. Int J Colorectal Dis 1992;7:219-22.

11. Winde G, Reers B, Nottberg H, Berns T, Meyer J, Bunte H. Clinical and functional results of abdominal rectopexy with absorbable mesh-graft for treatment of complete rectal prolapse. Eur J Surg 1993;159:301-5.

12. Galili Y, Rabau M. Comparison of polyglycolic acid and polypropylene mesh for rectopexy in the treatment of rectal prolapse. Eur J Surg 1997;163:445-8.

13. Mollen RM, Kuijpers JH, van Hoek F. Effects of rectal mobilization and lateral ligaments division on colonic and anorectal function. Dis Colon Rectum 2000;43:1283-7.

14. Arndt M, Pircher W. Absorbable mesh in the treatment of rectal prolapse. Int J Colorectal Dis 1988;3:141-3.

15. Speakman CT, Madden MV, Nicholls RJ, Kamm MA. Lateral ligament division during rectopexy causes constipation but prevents recurrence: results of a prospective randomized study. Br J Surg 1991;78:1431-3.

16. Ripstein CB. Treatment of massive rectal prolapse. Am J Surg 1952;83:68-71.

17. Aitola PT, Hiltunen KM, Matikainen MJ. Functional results of operative treatment of rectal prolapse over an 11-year period: emphasis on transabdominal approach. Dis Colon Rectum 1999; 42:655-60.

18. Tjandra JJ, Fazio VW, Church JM, Milsom JW, Oakley JR, Lavery IC. Ripstein procedure is an effective treatment for rectal prolapse without constipation. Dis Colon Rectum 1993;36:501-7.

19. Schultz I, Mellgren A, Dolk A, Johansson C, Holmstrom B. Longterm results and functional outcome after Ripstein rectopexy. Dis Colon Rectum 2000;43:35-43.

20. Senapati A, Nicholls RJ, Thomson JP, Phillips RK. Results of Delorme's procedure for rectal prolapse. Dis Colon Rectum 1994; 37:456-60.

21. Tobin SA, Scott IH. Delorme operation for rectal prolapse. Br J Surg 1994;81:1681-4.

22. Gordon PH, Hoexter B. Complications of the Ripstein procedure. Dis Colon Rectum 1978;21:277-80.

23. Kuijpers HC. Treatment of complete rectal prolapse: to narrow, to wrap, to suspend, to fix, to encircle, to plicate or to resect? World J Surg 1992;16:826-30.

24. Frykman HM, Goldberg SM. The surgical treatment of rectal procidentia. Surg Gynecol Obstet 1969;129:1225-30.

25. Yakut M, Kaymakcioglu N, Simsek A, Tan A, Sen D. Surgical treatment of rectal prolapsed: a retrospective analysis of 94 cases. Int Surg 1998;83:53-5.

26. Himpens J, Cadiere GB, Bruyns J, Vertruyen M. Laparoscopic rectopexy according to Wells. Surg Endosc 1999;13:139-41.

27. Deen KI, Grant E, Billingham C, Keighley MR. Abdominal resection rectopexy with pelvic floor repair versus perineal rectosigmoidectomy and pelvic floor repair for full-thickness rectal 
prolapse. Br J Surg 1994;81:302-4.

28. Huber FT, Stein H, Siewert JR. Functional results after treatment of rectal prolapse with rectopexy and sigmoid resection. World J Surg 1995; 19:138-43.

29. McKee RF, Lauder JC, Poon FW, Aitchison MA, Finlay IG. A prospective randomized study of abdominal rectopexy with and without sigmoidectomy in rectal prolapse. Surg Gynecol Obstet 1992; 174:145-8.

30. Yoon SG, Kim KU, Noh KY, Lee JK, Kim KY. Laparoscopic suture rectopexy for rectal prolapse. J Korean Soc Coloproctol 2002;18: 89-94.

31. Kellokumpu IH, Vironen J, Scheinin T. Laparoscopic repair of rectal prolapse: a prospective study evaluating surgical outcome and changes in symptoms and bowel function. Surg Endosc 2000; 14:634-40.

32. Heah SM, Hartley JE, Hurley J, Duthie GS, Monson JR. Laparoscopic suture rectopexy without resection is effective treatment for full-thickness rectal prolapse. Dis Colon Rectum 2000;43: 638-43.

33. Kessler H, Jerby BL, Milsom JW. Successful treatment of rectal prolapse by laparoscopic suture rectopexy. Surg Endosc 1999;13: 858-61.

34. Bruch HP, Herold A, Schiedeck T, Schwandner O. Laparoscopic surgery for rectal prolapse and outlet obstruction. Dis Colon Rectum 1999;42:1189-94.

35. Benoist S, Taffinder N, Gould S, Chang A, Darzi A. Functional results two years after laparoscopic rectopexy. Am J Surg 2001; 182:168-73.

36. Darzi A, Henry MM, Guillou PJ, Shorvon P, Monson JR. Stapled laparoscopic rectopexy for rectal prolapse. Surg Endosc 1995;9: 301-3.

37. Boccasanta P, Venturi M, Reitano MC, Salamina G, Rosati R, Montorsi M, et al. Laparotomic vs. laparoscopic rectopexy in complete rectal prolapse. Dig Surg 1999;16:415-9.

38. Stevenson AR, Stitz RW, Lumley JW. Laparoscopic-assisted resection-rectopexy for rectal prolapse: early and medium followup. Dis Colon Rectum 1998;41:46-54.

39. Muir EG. Rectal prolapse. Proc R Soc Med 1955;48:33-44.

40. Baker R, Senagore AJ, Luchtefeld MA. Laparoscopic-assisted vs. open resection: rectopexy offers excellent results. Dis Colon Rectum 1995;38:199-201.

41. Blatchford GJ, Perry RE, Thorson AG, Christensen MA. Rectal prolapse: rational therapy without foreign material. Neth J Surg 1989;41:126-8.

42. Jacobs LK, Lin YJ, Orkin BA. The best operation for rectal prolapse. Surg Clin North Am 1997;77:49-70.
43. Bachoo P, Brazzelli M, Grant A. Surgery for complete rectal prolapse in adults. Cochrane Database Syst Rev 2000;(2):CD001758.

44. Pescatori M, Interisano A, Stolfi VM, Zoffoli M. Delorme's operation and sphincteroplasty for rectal prolapse and fecal incontinence. Int J Colorectal Dis 1998;13:223-7.

45. Oliver GC, Vachon D, Eisenstat TE, Rubin RJ, Salvati EP. Delorme's procedure for complete rectal prolapse in severely debilitated patients. An analysis of 41 cases. Dis Colon Rectum 1994;37:461-7.

46. Watts AM, Thompson MR. Evaluation of Delorme's procedure as a treatment for full-thickness rectal prolapse. Br J Surg 2000;87: 218-22.

47. Liberman H, Hughes C, Dippolito A. Evaluation and outcome of the delorme procedure in the treatment of rectal outlet obstruction. Dis Colon Rectum 2000;43:188-92.

48. Kim DS, Tsang CB, Wong WD, Lowry AC, Goldberg SM, Madoff $\mathrm{RD}$. Complete rectal prolapse: evolution of management and results. Dis Colon Rectum 1999;42:460-6.

49. Xynos E, Chrysos E, Tsiaoussis J, Epanomeritakis E, Vassilakis JS. Resection rectopexy for rectal prolapse. The laparoscopic approach. Surg Endosc 1999;13:862-4.

50. Agachan F, Reissman P, Pfeifer J, Weiss EG, Nogueras JJ, Wexner SD. Comparison of three perineal procedures for the treatment of rectal prolapse. South Med J 1997;90:925-32.

51. Ramanujam PS, Venkatesh KS, Fietz MJ. Perineal excision of rectal procidentia in elderly high-risk patients: a ten-year experience. Dis Colon Rectum 1994;37:1027-30.

52. Williams JG, Rothenberger DA, Madoff RD, Goldberg SM. Treatment of rectal prolapse in the elderly by perineal rectosigmoidectomy. Dis Colon Rectum 1992;35:830-4.

53. Prasad ML, Pearl RK, Abcarian H, Orsay CP, Nelson RL. Perineal proctectomy, posterior rectopexy, and postanal levator repair for the treatment of rectal prolapse. Dis Colon Rectum 1986;29: 547-52.

54. Takesue Y, Yokoyama T, Murakami Y, Akagi S, Ohge H, Yokoyama Y, et al. The effectiveness of perineal rectosigmoidectomy for the treatment of rectal prolapse in elderly and high-risk patients. Surg Today 1999;29:290-3.

55. Yoon SG, Cho BW, Lee JK. Evaluation of Delorme-Thiersch procedure as a standard treatment for full-thickness rectal prolapse. J Korean Soc Coloproctol 2004;20:S86.

56. Yoon SG, Kim CS, Yoon JS, Noh KY, Park DH, Lee JK, et al. Altemeier's vs Delorme's procedure for complete rectal prolapsed. J Korean Soc Coloproctol 2002;18:S139.

57. Yoon SG, Kim SH, Lee JK, Kim KY. Laparoscopic unilateral suture rectopexy vs Delorme's procedure for complete rectal prolapsed. J Korean Soc Coloproctol 2007;23:S147. 